\title{
Erratum zu: Ist Blockchain das Ende der Banken? Zur Bedeutung von Schulden und Banken in kapitalistischen Ökonomien
}

\section{Barbara Brandl}

Online publiziert: 11. Januar 2021

(C) Springer Fachmedien Wiesbaden GmbH, ein Teil von Springer Nature 2021

\section{Erratum zu:}

Köln Z Soziol 2020

https://doi.org/10.1007/s11577-020-00716-w

Leider wurde vom Verlag versehentlich das falsche Eingangsdatum eingefügt, korrekt muss es heißen:

Eingegangen: 27. November 2019

Der Originalbeitrag wurde korrigiert.

Die Online-Version des Originalartikels ist unter https://doi.org/10.1007/s11577-020-00716-w zu finden.

B. Brandl $(\bowtie)$

Institut für Soziologie, Goethe Universität Frankfurt am Main

Hauspostfach 10, 60629 Frankfurt am Main, Deutschland

E-Mail: brandl@soz.uni-frankfurt.de 